


\section{Alfredo Gracia Vicente: del exilio republicano al jardín alfonsino}

Roberto Kaput González Santos Universidad Autónoma de Nuevo León

Resumen:

Nostalgia del territorio perdido e incorporación del sujeto en un nuevo entorno son los temas que contrapuntean la obra intelectual de Alfredo Gracia Vicente. Ellos definen sus múltiples labores como maestro. Dentro de la locación institucional del magisterio, ejerció en repetidas ocasiones la función de antólogo. Esta fue su manera de recuperar la tradición que le arrebatara la experiencia del exilio y la estrategia que implementó en la formación de seres estéticos más allá de las aulas. El libro ...del jardín de don Alfonso llega a nosotros como un documento que recrea el diálogo que sostuvo el asturiano con los escritos de Alfonso Reyes. De manera temprana (1907-1927), el regiomontano había creado las bases para el intercambio cultural entre los intelectuales españoles y latinoamericanos. Hacer del hispanismo un espacio habitable y un corredor de intercambio cultural fue el interés común de estos dos pensadores. Este ámbito histórico, sentimental y estético le brindaba una unidad superior a todos los participantes, sin me- 
noscabo de sus prerrogativas. En su faceta de antólogo, por tanto, Gracia engrosa las filas del Estado Estético que Robert Conn rastrea en la obra de Reyes: el marco donde la cultura de una comunidad es representada por las instituciones del arte y la literatura.

Palabras clave: guerra civil española, exilio, hispanismo, historia intelectual.

Abstract:

Nostalgia for the lost territory and incorporation of the subject in a new environment are the issues that are the counterpoint of Alfredo Gracia Vicente's intellectual work. These elements define his multiple roles as an educator. Within the institutional location of his teaching, he repeatedly exercised the function of an anthologist. This was his way of recovering the tradition that the experience of exile took, and the strategy implemented in the creation of aesthetic beings beyond the classroom. The book ...del jardín de don Alfonso comes to us a document that recreates the dialogue that Gracia had with the writings of Alfonso Reyes. Early on (1907-1927), the regiomontano had laid the groundwork for cultural exchange between Spanish and Latin American intellectuals. Making Hispanismo a living space and a cultural-exchanged corridor was the common interest of these thinkers. This historical, sentimental and aesthetic place gives a higher unity to all participants without disrupting their prerogatives. Therefore, in his role of anthologist Gracia is part of the Aesthetic State that Robert Conn tracks in the work of Alfonso Reyes: the framework where a communal culture is represented by the institutions of art and literature.

Keywords: Spanish Civil War, Exile, Hispanism, Intellectual history. 
De nuevo estoy en pie frente a mi mundo el mundo que creé para mis sueños con sus árboles altos florecidos.

\section{Pedro Garfias}

Ya me han oido decir (con fingido valor) que "soy el siglo veinte".

Alfredo Gracia Vicente

\section{El maestro}

T a figura de Alfredo Gracia Vicente es esquiva tanto en el exilio _como en su obra. Por un lado, su historia personal se confunde con el destino del millón de personas que abandonaron la península ibérica entre 1936 y 1939; por otro, su obra intelectual no se ajusta al modelo clásico de autor. Antes que otra cosa, este aragonés nacido en 1910 en Castel de Cabra, provincia de Teruel, fue un maestro. Lo fue en las trincheras españolas y en su obra regiomontana. En el libro homenaje que publicó la Universidad Autónoma de Nuevo León en 2010, Isabel Ortega Ridaura lo presenta en la noche del campo republicano, rodeado de soldados a quienes enseña a leer (Gracia, 2010: 16); Alfonso Rangel Guerra lo considera miembro de la generación de promotores culturales que modelaron el campo cultural regiomontano en la segunda parte del siglo XX (112); mientras que Humberto Salazar destaca la influencia que ejerció sobre los pintores que se formaron en el Taller de Artes Plásticas de la UANL y el grupo de escritores de la revista Apolodionis (102).

El problema con la obra de algunos maestros es que está hecha de memoria, y la memoria, como señala la antropóloga Marcela Valdata, "implica remitir a un pasado que en algún momento y por alguna situación determinada quedó en el olvido” (173). En el 
caso de Gracia Vicente ese olvido debe mucho a los acontecimientos políticos que lo obligaron a dejar España en 1939, pero también a una tarea pendiente: "la recuperación de su obra escrita, por ahora dispersa en periódicos, revistas, catálogos, presentaciones de libros y conferencias” (Gracia, 1996a: 8), como señalara en 1996 Reyes Tamez Guerra, entonces rector de la UANL. Si bien es cierto que de entonces a la fecha se han hecho algunos avances, ${ }^{1}$ la labor de rescate y valoración de su obra apenas comienza a perfilarse, sobre todo porque ésta rebasa el universo de lo escrito. La entrevista que en 1986 le hiciera Nora Guzmán para el periódico El Porvenir señala rumbos de futuras investigaciones: Gracia Vicente fue el primer librero oficial del Tecnológico de Monterrey, introdujo en el mercado local títulos de editoriales argentinas (Sudamericana) y espańolas (Aguilar), fundó la primera galería permanente en la ciudad, organizó lecturas y exposiciones echando mano del talento y disponibilidad de sus amigos (Gracia, 2010: 86-88). La librería Cosmos, primero, y el espacio Arte y Libros, después, fueron puntos de reunión para los escritores Pedro Garfias, Dámaso Alonso, Raúl Rangel Frías, José Alvarado, Gabriel Zaid, Alfonso Rangel Guerra, Luis Astey, Ernesto Rangel Domene, Carmen Alardín; Guillermo Ceniceros, Gerardo Cantú, Vicente Rojo, Francisco Toledo y Saskia Suárez llegaron a exponer en sus salas; también en sus visitas a Monterrey Alfonso Reyes solía parar en la librería de la calle Morelos y pedir a la empleada en turno: "Sube y dile a mi españolito que baje" (Gracia, 1996a: 105).

${ }^{1}$ En 2010 la Universidad Autónoma de Nuevo León reeditó dos libros: Del jardín de don Alfonso y Alfredo Gracia Vicente. Homenaje. El año siguiente la misma institución publicó Arte, con mayúscula, título que rescata algunos textos inéditos y otros aparecidos en los cuadernillos De arte y de letras I-II, Avance a los apuntes elementales de estética y arte I-II y las primeras páginas de la incompleta tercera parte. En esta labor de rescate destacan los nombres de Celso José Garza Acuña, Jessica Nieto y Alfredo Gracia Aguilar. 
Como se ve, las empresas culturales de Gracia Vicente apuntalaron los esfuerzos de aquellas instituciones llamadas a fomentar la educación humanista en un entorno que históricamente ha desdeńado todo valor que se aleje de la ética de trabajo que fomenta la élite empresarial. Otro de los temas pendientes de investigar a fondo, por tanto, es su paso por la Escuela de Verano y la Facultad de Ciencias de la Comunicación de la UANL, el Centro de Educación Artística Alfonso Reyes del INBA, el Instituto de Estudios Superiores de Arte A. C. y la Universidad Mexicana del Noreste. El carácter expansivo de esta faceta de su obra respondía a un principio sencillo: "la cultura no se debe imponer, pues así nadie la quiere, sino que se tienen que ir creando espacios para que esté al alcance de todos" (Gracia, 2010: 111).

Con el propósito de recuperar parte de esa memoria y estudiar la manera en que Gracia Vicente fue creando esos espacios, en la primera parte de este ensayo comentaré dos textos que reproducen la cartografía sentimental de una vida arrojada más allá de los confines de la patria. Nostalgia del territorio perdido e incorporación del sujeto en un nuevo entorno son los dos temas que contrapuntean la conciencia de los transterrados, que por esta vía superan el dolor y las restricciones de un nacionalismo romo. En la segunda, echaré mano principalmente de aquellos documentos que testifican su salida de España y su trato con la burocracia de otras naciones, puesto que, a quien se ve forzado a escapar, no se le puede pedir que cargue con otra cosa que los documentos que la guerra y las fronteras imponen. En la tercera hablaré, finalmente, de su labor de antólogo, que fue su manera de recuperar la tradición que le arrebatara la experiencia del exilio y la estrategia que implementó en la formación de seres estéticos más allá de las aulas. Es en este punto donde su trabajo entronca con la obra de Alfonso Reyes, quien de manera temprana (1907-1927) creó las bases para el intercambio cultural entre los intelectuales del mundo hispáni- 
co. En ...del jardín de don Alfonso, antología publicada por el gobierno del Estado de Nuevo León en 1989, Gracia Vicente ordena ese legado siguiendo la idea de un espacio comunitario por el que habrán de transitar libremente los lectores llamados a engrosar la tradición del hispanismo.

\section{Contrapunto amoroso}

Como tantos españoles republicanos, Alfredo Gracia Vicente conoció el destierro. En la ficha personal del sitio electrónico exiliad@s se responde con un escueto “No” a la pregunta “¿Retornaste definitivamente a Espańa?" Los años que pasara en Teruel, Barcelona, Tenerife y Gerona quedan ocultos tras la experiencia colectiva de la guerra. De ésta se conocen los episodios generales, pero su enumeración apenas permite asomarse a la tragedia personal de los actores. Es un problema de escalas. Como acertadamente señala Edward Said, el siglo XX no sólo masificó la experiencia del exilio, al hacerlo también situó su cabal comprensión más allá de la estética y las humanidades (2010: 138). En otras palabras, si nos limitamos a afirmar que el exilio republicano fue útil en el desarrollo del pensamiento humanista en México — como lo fue- o si sostenemos que algunos de sus protagonistas enriquecieron las artes del país — como lo hicieron—, omitimos la dimensión más inmediata del exilio: la pérdida que en un punto determinado de la historia padecieron cientos de miles de personas, el antagonismo o indiferencia de aquellos que contribuyeron a su expatriación, privándolos de un territorio que albergaba familia y tradiciones. El espacio del exilio se configuraría entonces alrededor de las políticas de masas, abstracción terrible que en el caso de Gracia Vicente se materializó en el campo de Saint-Cyprien. Si en Reflexiones sobre

2 Subvencionado por el Ministerio de Trabajo e Inmigración en 2009 y el Ministerio de Empleo y Seguridad Social en 2011. 
el exilio Said reivindica el discurso que producen algunos de los sujetos en condición de extraterritorialidad, lo hace en oposición directa a las instituciones que los empuja a encarar ese destino, es decir, a la causa misma del exilio. En "Mestizo cultural", un Gracia Vicente de 85 ańos resume el proceso que los transterrados hubieron de encarar antes de superar la ausencia espańola:

No veníamos a conquistar. Ya veníamos conquistados. Nuestra salvación consistía en incorporarnos a una tierra libre. Y lo conseguimos. Para nosotros México fue el Más allá, el Plus ultra legendario y mitológico. Pero había que superar la ausencia; veníamos del dolor, pero era un dolor tan entrañable como el amor. Unos más pronto, otros más tarde, creo que nuestra recuperación y superación del dolor ha sido general. Los transterrados (José Gaos, 1902-1969), hemos dejado de serlo por la vía del enriquecimiento moral. Mi México es mi hogar y mi amor; mi España es mi nostalgia, casi vencida por la dicha de su presencia libre y democrática. Siento además, hablo por mí, que puedo amar simultáneamente y con igual intensidad a España y a México, porque ni el uno ni el otro país me exigen otra cosa (2010: 25).

Esta nota brevísima, que no alcanza la media página en el libro homenaje que publicó la UANL, abre la sección titulada "Mis cuatro amores territoriales". De acuerdo con el discurso de recepción de la medalla Diego de Montemayor, estos cuatro amores son: "Castel de Cabra, el pueblo serrano y aragonés donde nací; Barcelona, perla del mar latino, donde aprendí a vivir; Tampico, mi primer hogar en México; Monterrey, mi definitiva morada, gallarda ciudad, hija de su misma fuerza, con el aliento de sus nobles montañas" (199). Pero de muchas maneras reproduce también la cartografía, los empeños de una vida arrojada a ese más allá que supone todo exilio.

Todo enriquecimiento moral surgido del desarraigo supone la acción de incorporarse, esto es, de introducir en el propio cuerpo los asuntos de otra tierra. El más allá del escrito de Gracia Vicen- 
te delata por tanto dos marcas: primero la histórica del destierro, la ausencia de una cultura que se presentifica en nostalgia, dolor tan entrañable como el amor que sólo se padece; la segunda la incorporación dinámica de otra tierra que se transforma en hogar tan pronto como el sujeto encuentra otros amores en donde enriquecer la tradición negada. El transterrado deja de serlo incorporándose e incorporando al otro, se recupera en el cruce de culturas, en la libertad de amar a dos países que no le exigen nada más. Esta pluralidad cultural suscita en la conciencia del exiliado dimensiones superpuestas: Castel de Cabra y Tampico, Barcelona y Monterrey o cualquier otra combinación posible entre estos cuatro amores territoriales esparcidos entre México y Espańa. Said califica de contrapuntística a esta clase de conciencia, y le atribuye la capacidad de desmantelar toda ortodoxia:

Para un exiliado, los hábitos, expresiones o actividades en el nuevo entorno inevitablemente ocurren contra la memoria de las mismas cosas en otro ambiente. Ambos entornos, el nuevo y el antiguo, son vívidos, actuales y ocurren contrapuntísticamente. Existe un gozo especial en esta clase de percepción, especialmente si el exiliado es consciente de que dicha yuxtaposición desmantela todo juicio ortodoxo (2010: 148).

La originalidad de Alfredo Gracia Vicente no radica en declarar que puede amar simultáneamente y con igual intensidad a Espańa y México, después de todo trabajó a pulso en cultivar cada uno de estos amores, sino en superar toda restricción política o nacional con las siguientes palabras: "Que la PAZ sea con todos los hombres, tengan o no tengan buena voluntad; por el sólo hecho de pertenecer a la especie. Que el planeta venga a ser el lugar común” (2010: 25). Quien escribe es un hombre que conoció el destierro y cuya historia personal se confunde con el destino del millón de personas que abandonaron España a causa de la guerra. Lo que 
nos remite al principio de este apartado. Pero antes de reconstruir su exilio diré que Alfredo Gracia Vicente murió en la clínica Osler de Monterrey. Héctor Maza afirma que un día antes el maestro impartió su última clase a Isabel Ortega Ridaura, nieta de una pareja de refugiados españoles con los que trabó amistad durante sus días de librero en Tampico. Con ella habría charlado de Gonzalo de Berceo (109). Y si bien es cierto que nunca regresó definitivamente a España, se esforzó hasta el último día por hacer del hispanismo que profesaba un espacio habitable y un corredor de intercambio cultural.

\section{Papeles de un exilio}

No empleo las reflexiones del palestino Edward Said para hablar del español Gracia Vicente por mero capricho. Mientras investigaba me di cuenta de que el problema es efectivamente de escala. El artículo de Said me permitió entender dos cosas: primero, que para contar la primera parte del exilio de Gracia Vicente necesitaba fundir su imagen con la de todos aquellos espańoles que de enero a abril de 1939 buscaron refugio en el departamento francés de los Pirineos Orientales; segundo, que el carácter impersonal del destierro coincide, al menos en su caso, con el tipo de documentos que se pueden consultar. Al fundador de la librería Cosmos en Monterrey no le agradaba escribir sobre la guerra civil. En "Pedro Garfias, pastor de soledades", apunta: "En 1936 empieza la guerra civil española. Ustedes saben lo que pasó. Hay más de seis mil libros que hablan de nuestra guerra. Y un millón de muertos que se niegan a ser definitivamente enterrados" (Gracia, 1996a: 140). No agrega más. Su testimonio más directo ha de buscarse entonces en la recuperación y promoción de los poetas identificados con la República: Pedro Garfias, Federico García Lorca, Ángela Figuera Aymerich, León Felipe. El resto de la información cae en la cate- 
goría de lo que el escultor Cuauhtémoc Zamudio llamó el anecdotario: se dice que cuando el comisario de guerra supo que había un soldado con dotes literarias en el regimiento de infantería lo retiró del frente y lo mandó colaborar en el boletín informativo que por entonces dirigía Miguel Hernández (Gracia, 2010: 16); que ese mismo recluta se ocupó más tarde de montar un periódico mural itinerante sobre un burro que la tropa llegó a conocer como "el burro ilustrado" (16-17); que ese hombre ya viejo se enorgulleció siempre de haber ejercido la profesión de maestro entre sus compañeros y de no haber disparado un solo tiro en sus años de miliciano (118). No obstante, de aquel tránsito de ciudadano español a asilado político, sólo se cuenta con cuatro documentos: una cartilla militar expedida en Barcelona en 1931, una carta mecanografiada dirigida a su esposa el 13 de noviembre de 1938, un pasaporte emitido por el consulado de Espańa en Niza el 15 de febrero de 1939 y un formulario del American Foreign Service llenado en París el 19 de septiembre de 1939 y sellado en Nueva York el 16 de octubre de ese mismo año.

La experiencia más inmediata del exilio raramente aparece en la literatura. Ésta ha de buscarse en los formularios oficiales que las instituciones gubernamentales llenan por miles en un momento de emergencia, en las cartas que llegan hasta nosotros como un acto de coraje y amor del destinatario que las conserva en su huida. Escribe el soldado republicano en la carta del 13 de noviembre de 1938: "Te repito mi máxima: CONFIANZA Y OPTIMISMO. Que seas tú la que des el ejemplo de firmeza entre los que a tu lado vacilen" (39). Uno puede imaginar las dos hojas con el membrete de la 139 Brigada, 49 División, viajando en la blusa de María Luisa Aguilar Galcerán, su compañera. Apunta Said:

Para concentrarse en el exilio como una forma contemporánea de castigo político, se deben cartografiar aquellos territorios que se encuentran más allá del espacio que rotula la propia literatura del 
exilio. Debe dejarse de lado a Joyce y a Nabokov e introducir en su lugar a las masas incontables [...] sin perspectiva de regresar a casa, armadas tan sólo de una tarjeta de racionamiento y un número de agencia (139).

Exploremos el territorio. La huida a los Pirineos Occidentales inicia con la caída de Tarragona el 15 de enero de 1939. Francia abre su frontera, cerrada desde el 13 de junio de 1938. El 21 de enero Barcelona es bombardeada. Tres días después el pánico se apodera de la ciudad tras darse a conocer la salida del gobierno de la República y la Generalitat. Caravanas multitudinarias se ponen en marcha en dirección a la frontera francesa. Las tropas nacionalistas entran a Barcelona el 26 de enero. Los testigos afirman que no se disparó un sólo tiro. Era una plaza rendida. Ese mismo día Francia cierra la frontera con España. El número de personas estacionadas se calcula en ciento de miles. Todos los días llegan más. Tras los bombardeos de Girona y Figueres el 28 de enero, el ministro español Julio Álvarez del Vayo consigue finalmente que el gobierno francés acepte la entrada de civiles. La entrada de combatientes es pactada hasta el 5 de abril con la condición de que entreguen las armas y acepten ser internados en campos de concentración. De acuerdo con la historiadora Lidia Bocanegra Barbecho, el último día en que se registraron ingresos de forma masiva fue el 10 de febrero de 1939. En menos de un mes Francia había recibido 465 mil refugiados. Uno de ellos era Alfredo Gracia Vicente.

Pasaporte No. 50 expedido en el consulado de España en Niza con fecha 15 de febrero de 1939: "Países para los cuales este pasaporte es válido: Francia, Europa y América” (Gracia, 2010: 41). ¿Sabía Gracia Vicente que su destino final, como indica el formulario del American Foreign Service, era México? En un cuestionario del sitioweb exiliad@s: se encuentra la siguiente información: "Primer campo de concentración/centro de albergue: Saint-Cyprien. Periodo de internamiento: menos de un mes”. ¿Cuánto es menos de un 
mes? Se sabe que Francia permitió el paso de excombatientes hasta el día 5 de febrero de 1939 y que el campo de Saint-Cyprien fue montado el día 8 para recibir a los refugiados que entraron por Le Perthus y Cérbere entre el 5 y 9. ¿Basta una semana para entrar y salir de un sistema burocrático rebasado, llegar a Niza y tramitar el pasaporte? ${ }^{3}$ Por aquellos días su suegro, don Mario Aguilar, se desempeńaba como diplomático en Francia. ¿Es él quien tramita el pasaporte? En el sitio exiliad@s se hayan los siguientes datos: "Primer pueblo/ciudad de destino: Niza. Año de entrada: 1939. Periodo de permanencia: menos de un año. Medio de entrada: Andando”. ¿Cómo rescatar la biografía de un hombre cuando su historia se confunde con la de 465 mil refugiados?

Imaginemos masas incontables de refugiados sin probabilidades de regresar a casa portando los documentos indispensables para su tránsito. En el pasaporte No. 50, que mencionamos antes: "Préfecture de police. No. 56216. Visa de sortie de France a destination de l'Amérique par le poste frontière de Havre. Paris le 5-10-39" (Gracia, 2010: 41). Las vacilaciones políticas del gobierno francés con respecto a la emigración española debieron empujar a los Gracia a buscar ayuda en los cuáqueros, organización que tramitó los permisos necesarios para que la familia continuara su peregrinaje. En la Application for transit certificate, American Foreign Service, No. 480, Paris, France, September 19th 1939 se consigna:

I, the undersigned APPLICANT FOR A NONIMMIGRANT VISA, declare that my full and true name is Alfredo GRACIA Vicente.

${ }^{3}$ El documento declara como fecha de nacimiento el día 7 de agosto de 1910, información tomada, imagino, de la cartilla militar, primer documento oficial del que disponemos. Esta fecha no coincide con el registro de extranjeros expedido en la Ciudad de México el día 19 de diciembre de 1939 ni con la Carta de Naturalización Mexicana que le fue otorgada en Tampico el 15 de octubre de 1940. Allí se consigna como fecha de nacimiento el 6 de agosto de 1910. Error de la administración mexicana, seguramente. 
That I was born 7 August 1910 at Castel de Cabra, Spain. [...] That I am a citizen of Spain — now without country, and am the bearer of passport No. 50, issued on 15 February 1939 by Spanish Consulate at Nice, France, valid until 15 February 1940. That I am married and the name of my wife is María Luisa Aguilar de Gracia. [...] My fixed domicile was at Spain; will be Mexico. That I arrived in France on February 1939 for the purpose of travel political refugee. That my occupation for the last two years was teacher. That my purpose in going to the United States is passing in transit to Mexico (42).

De golpe la patria desaparece. El carácter autorreferencial de los documentos que produce la maquinaria estatal instaura un espacio burocrático en el que los ciudadanos sin país se transforman en refugiados políticos. Éstos no terminan de instalarse porque los permisos van siempre acompañados de una indicación temporal que los empuja a seguir adelante, como se advierte en la Application for transit certificate, American Foreign Service, No. 480: "Admitted at New York, N.Y. on Oct. 16 1939, under paragraph 3 section 3, Immigration Act of 1924, for 15 days" (43).

Se cuenta que Constanza Gracia Vicente recibió a la pareja con pasaportes puertorriqueños falsos, deseando que su hermano y su cuñada se quedaran a vivir con ella en Nueva York, ciudad a la que había trasladado su taller barcelonés de costura. Sin embargo, el matrimonio optó por seguir adelante. Así consta en el Pasaporte No. 50, citado previamente: "Estados Unidos Mexicanos, Servicio de Migración, noviembre 30, 1939, Veracruz, Veracruz. Admitido como asilado político, vapor Siboney" (41). Con 29 años y tres documentos de identidad llega Alfredo Gracia Vicente a México: la cartilla militar del ejército espańol No. 2103260 que acredita la identidad del soldado y lo declara útil para todo servicio; pasaporte No. 50 del consulado de Espańa en Niza, documento que le reconoce la nacionalidad española y le concede permiso de viajar a Eu- 
ropa y América; solicitud de tránsito del American Foreign Service No. 480, donde se le declara ciudadano sin país y se estipula que su destino final es México. Es de suponer que María Luisa Aguilar de Gracia guardaba entre sus ropas la carta.

\section{El jardín comunitario}

El enriquecimiento moral que Alfredo Gracia Vicente declara haber experimentado en México surge, me parece, de su labor como maestro. En los múltiples oficios que desempeñó en Tampico y Monterrey (librero, galerista, promotor cultural, conferenciante, articulista, antólogo) se percibe un mismo interés: contribuir a la formación del hombre estético, complemento del hombre sabio, el fabricante, el político y el economista. En "El arte es para todo" desarrolla esta idea:

Se da en el hombre un sentimiento, el de la belleza, que los hechos sociales conforman según el tiempo y el espacio en que estos hechos se producen. [...] El Arte, en singular y con mayúsculas, es un bienhacer original y comunicativo por medio del cual se propicia en nosotros, en todos nosotros, la fruición estética. El arte es para todos y forma parte de nuestras vidas; [...] pero no todos lo disfrutamos con la misma intensidad ni estamos preparados para emitir juicios objetivos. [...] A las diferencias de niveles culturales, económicos e informativos entre las distintas clases sociales, [...] se junta la carencia de planes ordenados y armoniosos que encaucen la actividad artística de manera que la sociedad entera se beneficie de sus productos. [...] El arte de expresión humanística es para todos. La intensidad de la fruición estética depende de nuestra cultura, de nuestra sensibilidad, de nuestra atención y de nuestra voluntad. La cultura se puede incrementar, la sensibilidad se puede afinar, la atención se puede educar, la voluntad decide los resultados (163-164). 
El primer punto que quisiera resaltar es el de la belleza como sentimiento histórico. El maestro, para apoyar su argumento, cita a Hegel, de suerte que dicho sentimiento habrá de entenderse como la historia de los Estados que se encaminan a un orden general, no la del accidente. Escribe más adelante: "El hombre se puede encontrar involuntariamente en el caos, pero no por mucho tiempo. La estética, ciencia humanística por excelencia, tiende al orden, sólo se satisface en el orden, es el orden mismo" (164). El segundo punto es el del arte como bienhacer original y comunicativo que propicia el gozo estético. Los objetos estéticos son, pues, un medio para entrar en contacto con aquello que ya forma parte de nosotros: "En sus aspectos más trascendentes, el hombre, así lo dice Hegel, se ha servido del arte como de un medio de tomar conciencia de las ideas y de los intereses más elevados de su espíritu" (164). Pero esa cualidad del arte, tercer y último punto, no se basta a sí misma, requiere de la estética, ciencia que de manera ordenada allana el camino para que la fruición estética sea un bien común. Pues bien, el enriquecimiento moral que Gracia Vicente extrajo de su tarea como formador de seres estéticos descansaba en el hispanismo.

Decir esto es decir poco, queda por aclarar qué entendía el asturiano por hispanismo. Salto a otro artículo que nos acerca un poco más a Alfonso Reyes. En "Raúl Rangel Frías y el exilio español", el autor introduce el nombre de cuatro pensadores ibéricos que modelan su hispanismo. El jesuita Juan de Mariana (1536-1623), autor de Historia general de España, asume, afirma, la idea unitaria de España sin menoscabo de las nacionalidades históricas que la componen. La idea de España como ámbito cultural común comprende ya a las colonias americanas, toda vez que existe el precedente de la defensa de los derechos de los naturales, encabezada por Francisco Suárez, Antonio de Montesinos y Bartolomé de las Casas. La noción de hombre soberano sería entonces una invaria- 
ble histórica no sólo del pueblo español sino también del mexicano. Allí están las reflexiones en torno al individualismo español de Ángel Ganivet y Miguel de Unamuno, allá las palabras de Rangel Frías: "Se impone la obra de aquello que hemos edificado juntos. Un viejo y nuevo mundo surgido de los antepasados, de sus combates y vicisitudes" (Gracia, 1985: 27).

El hispanismo de Gracia Vicente emerge entonces como la obra de todos los pueblos que enriquecieron moralmente este ámbito histórico, sentimental y estético, brindándoles una unidad superior sin quebranto de sus derechos. En la historia reciente este hispanismo habría cobrado forma jurídica en tres momentos: durante la República espańola, que reconoció las autonomías sin perder de vista la idea unitaria; con el gobierno de Lázaro Cárdenas, que devolvió a parte de la República su filiación con España; en la constitución democrática de 1978, que "se fundamenta en la indisoluble unidad de la nación española, patria común e indivisible de todos los espańoles, y reconoce y garantiza el derecho a la autonomía de las nacionalidades y regiones que la integran y la solidaridad entre todos ellos" (27-28). No obstante, también se habría manifestado en la cultura literaria; por ejemplo, en la obra de Alfonso Reyes.

Todos los intelectuales, señala Robert Conn, producen su obra desde una locación institucional específica (25). Se ha dicho que la tribuna principal de Gracia Vicente fue el magisterio. Dentro de éste, ejerció en repetidas ocasiones la labor de antólogo. Pedro Garfias, Ángela Figuera Aymerich y Alfonso Reyes son apenas tres de los autores que el maestro empleó en la formación de seres estéticos. El propósito de la antología ... del jardín de don Alfonso era, de acuerdo con Guillermo Yerena Magaña, su prologuista, "honrar y recordar a don Alfonso Reyes en el centenario de su natalicio, [...] para que nuevas generaciones conozcan la obra de uno de los más grandes y prolíficos escritores de México" (7). La pregunta se 
impone: de la obra monumental de Alfonso Reyes, ¿qué es lo que el antólogo quiere transmitir a la nueva generación de lectores?

El libro, que se divide en tres secciones, dos dedicadas a los jóvenes y una a los niños, abre con un texto de Cartones de Madrid. El tema de "La prueba platónica" es el amor a una idea, la Idea. Conforme la lectura avanza, el excursionista de este, digamos, jardín botánico, se percata de que la idea que da cohesión a la antología es el hispanismo, un hispanismo entendido como obra de lo que hemos edificado juntos, para emplear las palabras de Rangel Frías que tanto emocionaban a Gracia Vicente. Como en Reyes, esta experiencia estética es la base de la nación proyectada por el antólogo Gracia Vicente, no en vano la segunda parte del libro, titulada "Punto y seguido", cierra con doce fragmentos de la Cartilla moral que Reyes preparó en 1944 para el secretario de Educación Jaime Torres Bodet.

"Naturaleza, tiempo, historia y lengua son los fundamentos de nuestra identidad, pues en ellos se guardan las huellas de nuestra presencia física y espiritual" (1996a: 110-11), escribe Gracia Vicente en "Huellas hacia el mañana: mi página sobre Alfonso Reyes". Ésta, puede decirse, es la canción materna de "Las hazańas de Mistral", texto que aparece en la antología. Es también "la comunidad del esfuerzo por domeñar nuestra naturaleza brava y fragorosa" (Gracia, 1989: 14) de Visión de Anáhuac, que subsume en la política del mestizaje dos naciones históricas. En la misma página sobre Reyes, Gracia Vicente comenta el mural El origen de la América hispánica: Cortés y Malinche de José Clemente Orozco:

Impresiona, por su grandiosidad y verosimilitud, las figuras desnudas — desnudos de clásica estirpe artística- de Hernando de Cortés y doña Marina. Imágenes simbólicas de una nueva raza; preferiría decir, de un nuevo pueblo. Este símbolo está en el fondo de la identidad del mexicano: ahí están los orígenes. En las esencias de la identidad de lo mexicano figuran valores heredados 
y recreados por el pueblo nuevo. El mexicano, creador de una cultura propia, transita por una civilización que le pertenece y que lo enaltece ante el mundo (1996a: 104).

Tránsito del mexicano, entonces, por el hispanismo, ese corredor de intercambio cultural que Alfonso Reyes preconizara en "El congreso postal de Madrid", artículo que el regiomontano publica en aquella ciudad en 1920 y que el asturiano antologa en Monterrey en 1989. Sin embargo, ese tránsito ha de ser dinámico si aspira a ser creador, de ahí la apostilla que acompaña la historia del ermitaño y el rey Ricardo de Inglaterra: "Aquí exalta el ideal de la vida activa" (Gracia, 1989: 13). Esta es la kátharsis del "Misticismo activo" que predica Reyes en el libro El suicida: la transformación de los estados pasivos del alma en activos. Es por ello, acaso, que la antología reivindica "El derecho a la locura" en la figura del modisto francés que "sabe que el amor se disolvería si él no inventara, para nuestras mujeres, el nuevo modelo de la estación" (Gracia 1989: 15). En esta anécdota alfonsina que el maestro Gracia toma de Cartones de Madrid radica la posibilidad de un hispanismo moderno: el del delirio de los Caprichos de Goya, el del dinamismo de la picaresca de Mateo Alemán, el de los raros de la literatura española en los que ha reparado Azorín, el del escándalo del cubismo de Diego Rivera en Madrid.

En su faceta de antólogo, Gracia Vicente engrosa las filas de ese Estado Estético que Robert Conn rastrea en la obra de Reyes: el marco donde la cultura de una comunidad orgánica es representada por las instituciones del arte y la literatura (57). Como parte de esa minoría ilustrada, Gracia Vicente estima la contribución de todos sus miembros, que a partir de entonces se reconocen en un hispanismo que contiene diferentes tradiciones. Como maestro, sabe que la propedéutica que demanda esta clase de comunidad ha de erigirse en los terrenos de la infancia; como botánico del jardín alfonsino, sabe que la unidad superior del hispanismo ha de com- 
binar el gusto por el idioma común y la geografía local. De ahí que la tercera sección del libro, titulada "Palabras y más palabras, versos para los niños, desprendidos de los poemas de Alfonso Reyes" (Gracia 1989: 87), abra con "Romance de Monterrey":

Monterrey de las montañas, tú que estás a par de río;

fábrica de la frontera

$\mathrm{y} \tan$ mi lugar nativo

que no sé cómo no añado

tu nombre en el nombre mío (89).

La selección de este poema busca dar la bienvenida a los lectores más jóvenes, comunicarles su pertenencia a una lengua y a un territorio. Imposible participar del hispanismo que ordena el jardín alfonsino sin atender el carácter recursivo de su premisa: toda geografía se nombra en romance popular; todo romance popular nombra una geografía.

\section{Bibliografía}

“Alfredo Gracia Vicente”, 30 de abril de 2014, Proyecto e-xiliad@s, Ministerio de Empleo y Seguridad Social, Ministerio de Trabajo e Inmigración de España, disponible en://www.exiliadosrepublicanos.info/es/content/alfredo-gracia-vicente.

Conn, Robert T., 2000, The politics of philology: Alfonso Reyes and the invention of the Latin American literary tradition, Bucknell University Press.

Garfias, Pedro, 1962, Primavera en Eaton Hastings. Poema bucólico con intermedios de llanto, México, Era.

Gracia Vicente, Alfredo, 1985, De arte y de letras (I), Monterrey,

N.L., Ediciones de la Escuela Preparatoria No. 1 de la UANL. 
, 1986, De arte y de letras (II), Monterrey, Ediciones de la Escuela Preparatoria No. 1 de la UANL.

, 1989, ...del jardin de don Alfonso, Monterrey, Gobierno del Estado de Nuevo León.

, 1996a, De viva voz, Monterrey, UANL.

, 1996b, Avance a los apuntes elementales de estética y arte. Primera parte, Monterrey, Facultad de Ciencias de la Comunicación de la UANL.

,2011, Arte, con mayúscula. Monterrey, UANL.

Gracia Vicente, Alfredo et al., 2010, Alfredo Gracia Vicente: Homenaje, Monterrey, UANL.

Rangel Frías, Raúl, 1982, Secuencia de Reyes: las palabras. Contribución al homenaje nacional de Alfonso Reyes, Monterrey, SEP Nuevo León.

Reyes, Alfonso, 1986a, Obras completas, t. II. Visión de Anáhuac. Las visperas de España. Calendario, México, FCE.

, 1986b, Obras completas, t. III. El plano oblicuo. El cazador. El suicida. Aquellos dias. Retratos reales e imaginarios, México, FCE.

, 1996, Obras completas X. Constancia poética, México, FCE. , 2008, Cartilla moral, Mexicali, UABC / UANL.

Said, Edward W., 2000, Reflections on exile and other essays, Massachusetts, Harvard University Press, Cambridge.

Valdata, Marcela, 2010, "Memoria”, en Mónica Szurmuk y Robert McKee Irwin, Diccionario de estudios culturales latinoamericano, México, Instituto Mora / Siglo XXI editores.

(Recibido: 14 de enero de 2015, aceptado: 10 de marzo de 2015) 